\title{
Complement Consumption in Systemic Lupus Erythematosus Leads to Decreased Opsonophagocytosis In Vitro
}

\author{
Amanda Mitander, Ying Fei, Estelle Trysberg, Majd Mohammad, Zhicheng Hu, \\ Egidija Sakiniene, Rille Pullerits, and Tao Jin
}

ABSTRACT. Objective. Infections remain a major cause of morbidity and mortality in patients with systemic lupus erythematosus (SLE). The high prevalence of infections in SLE is attributed to both the disease and its treatments. The complement system plays an important role in host immune responses against invading microorganisms. We sought to provide the experimental and clinical evidence supporting the hypothesis that low levels of complement factors cause defective complement-mediated opsonization in patients with SLE.

Methods. Staphylococcus aureus was opsonized with sera from healthy individuals $(\mathrm{n}=16)$, SLE patients with normal $(\mathrm{n}=5)$ or low complement $(\mathrm{n}=8)$ levels. Phagocytosis of $S$. aureus by healthy human neutrophils was analyzed by an imaging flow cytometry-based method. We retrospectively examined the infection incidence in relation to complement levels in a cohort of 165 patients with SLE during a 1.5-year period. The association was analyzed for infection incidence and disease-related variables.

Results. Uptake of S. aureus by neutrophils was decreased when S. aureus was opsonized with sera from SLE patients with low complement levels compared to sera from healthy individuals and SLE patients with normal complement. In our SLE cohort, $44 \%$ of patients had at least 1 infection during the 1.5 years. No significant association was observed between complement levels and infection risk. Importantly, high-dose glucocorticoids (GC; prednisone $\geq 10 \mathrm{mg} /$ day) were the most important predictive factor for infections in patients with SLE.

Conclusion. Low complement levels affect bacterial opsonization in SLE blood and lead to downregulated phagocytosis by neutrophils. High-dose GC increase the infection risk in patients with SLE. (First Release September 1 2018; J Rheumatol 2018;45:1557-64; doi:10.3899/jrheum.171325)

Key Indexing Terms:

SYSTEMIC LUPUS ERYTHEMATOSUS GLUCOCORTICOIDS

From the Department of Rheumatology and Inflammation Research, Institution of Medicine, Sahlgrenska Academy at University of Gothenburg, Göteborg, Sweden; Department of Microbiology and Immunology, The Affiliated Hospital of GuiZhou Medical University, Guiyang, China; Department of Rheumatology, and Department of Clinical Immunology and Transfusion Medicine, Sahlgrenska University Hospital, Göteborg, Sweden.

Supported by the Swedish Medical Research Council (grant 523-20132750 to T. Jin), Professor Nanna Svartz Fond (grant 2016-00117 to T. Jin), Rune och Ulla Amlövs Stiftelse för Neurologisk och Reumatologisk

Forskning (grant to T. Jin), Adlerbertska Forskningsstiftelsen (grant to T. Jin), and Institute for Medicine, Gothenburg University. The funders had no role in study design, data collection and interpretation, or the decision to submit the work for publication.

A. Mitander, MD, Department of Rheumatology and Inflammation Research, Institution of Medicine, Sahlgrenska Academy at University of Gothenburg, and Department of Rheumatology, Sahlgrenska University Hospital; Y. Fei, MSc, Professor, Department of Microbiology and Immunology, The Affiliated Hospital of GuiZhou Medical University; E. Trysberg, MD, PhD, Department of Rheumatology and Inflammation Research, Institution of Medicine, Sahlgrenska Academy at University of Gothenburg, and Department of Rheumatology, Sahlgrenska University Hospital;

M. Mohammad, MSc, Department of Rheumatology and Inflammation Research, Institution of Medicine, Sahlgrenska Academy at University of Gothenburg; Z. Hu, MSc, Department of Rheumatology and Inflammation Research, Institution of Medicine, Sahlgrenska Academy at University of

\section{COMPLEMENT FACTORS INFECTION RISK}

Gothenburg, and Department of Microbiology and Immunology, The Affiliated Hospital of GuiZhou Medical University; E. Sakiniene, MD, PhD, Department of Rheumatology, Sahlgrenska University Hospital; R. Pullerits, $M D, P h D$, Associate Professor, Department of Rheumatology and Inflammation Research, Institution of Medicine, Sahlgrenska Academy at University of Gothenburg, and Department of Rheumatology, and Department of Clinical Immunology and Transfusion Medicine, Sahlgrenska University Hospital; T. Jin, MD, PhD, Associate Professor, Department of Rheumatology and Inflammation Research, Institution of Medicine, Sahlgrenska Academy at University of Gothenburg, and Department of Rheumatology, Sahlgrenska University Hospital.

Address correspondence to Dr. T. Jin, Associate Professor, Department of Rheumatology and Inflammation Research, Institution of Medicine, The Sahlgrenska Academy at the University of Gothenburg, Guldhedsgatan 10A, S-41346 Göteborg, Sweden.E-mail:tao.jin@rheuma.gu.se Accepted for publication June 4, 2018.

Infectious diseases are a major cause of morbidity and mortality in patients with systemic lupus erythematosus (SLE), accounting for $20-55 \%$ of all deaths in those patients ${ }^{1}$. Along with active disease and medical complications, infections are one of the 3 most common reasons for hospitalization in patients with SLE, causing significant clinical and economic consequences ${ }^{2}$.

Personal non-commercial use only. The Journal of Rheumatology Copyright @ 2018 . All rights reserved. 
The high prevalence of infections in patients with SLE has been attributed to both the disease (intrinsic factors) and its treatments (extrinsic factors). Corticosteroids, especially in high doses, are shown in numerous reports to significantly increase the susceptibility to infections ${ }^{3,4,5,6}$. The use of cyclophosphamide (CYC) is also known as a strong risk factor for infections in $\mathrm{SLE}^{7,8}$. For rituximab (RTX), it has been shown that the first 6 months after treatment and the use of more than 3 courses are associated with an increased susceptibility for infections ${ }^{4}$.

Besides the immunosuppressive treatments, patients with SLE appear to have intrinsic factors predisposing to infections. The phagocytic ability, chemotaxis, and production of reactive oxygen species are impaired in neutrophils isolated from patients with $\operatorname{SLE}^{9,10,11}$, which might be partially due to decreased tumor necrosis factor production by monocytes in patients with SLE ${ }^{12}$. Lymphopenia, a commonly observed hematologic disorder in untreated patients with SLE, was shown to be an independent risk factor for development of severe infections ${ }^{13}$.

The complement system, one of the essential components of the innate immunity, is also affected in SLE. The homozygous hereditary deficiency of complement components (e.g., C1q) is strongly associated with development of SLE and severe manifestations of the disease ${ }^{14,15}$. The expression of complement receptor 1 is downregulated in the leukocytes from patients with SLE, resulting in impaired clearance of immune complexes and invading microorganisms ${ }^{16}$. As a result of complement activation and consumption, the levels of complement proteins are often reduced in patients with active SLE ${ }^{17,18}$. Low levels of complement factors were shown to be an independent risk factor for development of severe infections and acquiring drug-resistant bacteria in patients with $\operatorname{SLE}^{3,7,13}$.

In our present study, we attempted to provide the experimental and clinical evidence supporting the hypothesis that low levels of complement factors cause defective complement-mediated opsonization of bacteria in sera of patients with SLE.

\section{MATERIALS AND METHODS}

Ethics, consent, and permissions. All patients gave informed consent prior to participation, and the studies were approved by the Ethics Committee at the Sahlgrenska Academy at the University of Gothenburg with approval numbers 433-11 and 449-12.

Serum samples from patients and healthy controls. Blood samples were collected from 13 patients with SLE attending the rheumatology clinics in Sahlgrenska University Hospital, Göteborg, in western Sweden. All patients fulfilled the 1997 updated American College of Rheumatology classification criteria for SLE ${ }^{19,20}$ as well as Systemic Lupus International Collaborating Clinics (SLICC) classification criteria from 2012 21 . Five of the included patients had normal $\mathrm{C} 3$ and $\mathrm{C} 4$ levels, and 8 patients had both low $\mathrm{C} 3$ and low $\mathrm{C} 4$ blood levels. A control group of 16 healthy staff members and $\mathrm{PhD}$ students (age range 25-49 yrs) in the Department of Rheumatology were included.

Sera and EDTA plasma were also collected simultaneously from 4 SLE patients with normal complement factor (C3 and C4) levels. To obtain the heat-inactivated sera, the patient sera were heated at $56^{\circ} \mathrm{C}$ for $60 \mathrm{~min}$.
Samples were aliquoted and stored at $-70^{\circ} \mathrm{C}$ until the time of analyses. $\mathrm{C} 3, \mathrm{C} 4$, and C3d levels in EDTA plasma were analyzed consecutively in the routine laboratory of the Department of Clinical Immunology of Sahlgrenska University Hospital.

Isolation of human neutrophils. Peripheral blood neutrophils were isolated from 1-day-old buffy coats from healthy blood donors. Neutrophils were purified, suspended in Krebs-Ringer glucose (KRG) phosphate buffer supplemented with $\mathrm{Ca} 2+(1 \mathrm{mM})$, and stored on ice until use ${ }^{22}$.

Identification of $C 3 b$ deposits on the Staphylococcus aureus surface. Green fluorescent protein (GFP)-expressing $S$. aureus were cultured overnight in tryptic soy broth (TSB) and then incubated with $10 \%$ normal sera, heat-inactivated sera, and EDTA-plasma from 4 patients with SLE, and C3-depleted sera (Quidel Corp.) in phosphate buffered saline (PBS) at $37^{\circ} \mathrm{C}$ for $30 \mathrm{~min}$. The serum-opsonized $S$. aureus $\left(5 \times 10^{6} / \mathrm{sample}\right)$ were washed, then placed on ice and stained with allophycocyanin (APC) mouse antihuman $\mathrm{C} 3 \mathrm{~b} / \mathrm{iC} 3 \mathrm{~b}$ (BioLegend) diluted 1:100 for $1 \mathrm{~h}$, before being analyzed on an imaging flow cytometer (ImageStreamX MkII Amnis and Image Data Exploration and Analysis software v.6.0) at $60 \times$ magnification.

Human neutrophil phagocytosis assay. An imaging flow cytometry-based method was used to analyze phagocytic capacity of human neutrophils, as previously described ${ }^{23,24}$. GFP-expressing $S$. aureus bacteria were cultured overnight in TSB, washed in PBS, and then incubated with $10 \%$ sera from healthy individuals and from patients with SLE in $\mathrm{KRG}$ at $37^{\circ} \mathrm{C}$ for $30 \mathrm{~min}$. Also, normal sera, heat-inactivated sera, EDTA plasma from 4 patients with SLE, and C3-depleted serum were used for S. aureus opsonization. The purified neutrophils $\left(1 \times 10^{6} /\right.$ sample $)$ were allowed to interact with opsonized $S$. aureus $\left(5 \times 10^{6} /\right.$ sample) at $37^{\circ} \mathrm{C}$ for $30 \mathrm{~min}$. The cells were then placed on ice and stained with APC mouse antihuman CD16 (BD Pharmingen) for $1 \mathrm{~h}$, before being analyzed on an imaging flow cytometer. Neutrophils were defined as the CD16-positive cells, and phagocytosis was analyzed in a single neutrophil. First, the intensity of GFP was used to determine whether the cell was associated with bacteria. Then, the internalization feature was used to determine whether the GFP-positive cells had internalized or merely bound the bacteria. Data are presented as the percentage of CD16-positive neutrophils with internalized S. aureus.

Inclusion and exclusion criteria in the SLE cohort. We identified all patients (a total of 525) with SLE diagnosis at the Rheumatology Department of Sahlgrenska University Hospital in Sweden during a 1.5-year study period (July 2014-December 2015). We chose only to include patients who were $<50$ years of age at the end of 2015 (283 patients), because infections in older patients are more multifactorial. Of those 283 patients, 200 individuals had registered blood levels of complement factors $(\mathrm{C} 3, \mathrm{C} 4$, and $\mathrm{C} 3 \mathrm{~d})$ during this study period. Finally, medical records of the patients were carefully reviewed and 165 patients who met the SLICC classification criteria from 2012 were included in the study (Figure 1).

Study approach. Information about the lowest and highest levels of C3, C4 and $\mathrm{C} 3 \mathrm{~d}$ measured during the study period were recorded, as well as information in medical records regarding infections and use of antibiotics during the same period. Likewise, current values of anti-dsDNA and the occurrence of leukopenia, neutropenia, and lymphopenia during the period of 1.5 years were noted.

Organ involvement, positive autoantibodies (antinuclear antibody, anti-dsDNA, anti-SSA, anti-SSB, anti-Sm, anti-RNP, anti-RiboP, anti-C1q, antiphospholipid antibodies, lupus anticoagulant), and pathologic hematologic status (hemolytic anemia, leukopenia, thrombocytopenia) since disease debut were used to ensure that the patients fulfilled the SLE classification criteria for inclusion (SLICC-2012).

The patients were divided into 3 groups according to $\mathrm{C} 3$ and $\mathrm{C} 4$ levels: normal, low, and very low level of complement. The boundary level between low and very low was placed one-third below the lowest normal cutoff level. For C3, the levels were $0.76-1.39 \mathrm{~g} / 1$ (normal), $0.50-0.75 \mathrm{~g} / 1$ (low), and $<0.50 \mathrm{~g} / 1$ (very low). For C4, the levels were 0.13-0.37 g/l (normal), $0.087-0.12 \mathrm{~g} / \mathrm{l}$ (low), and $<0.087 \mathrm{~g} / \mathrm{l}$ (very low). The average of the highest

Personal non-commercial use only. The Journal of Rheumatology Copyright (C) 2018. All rights reserved 

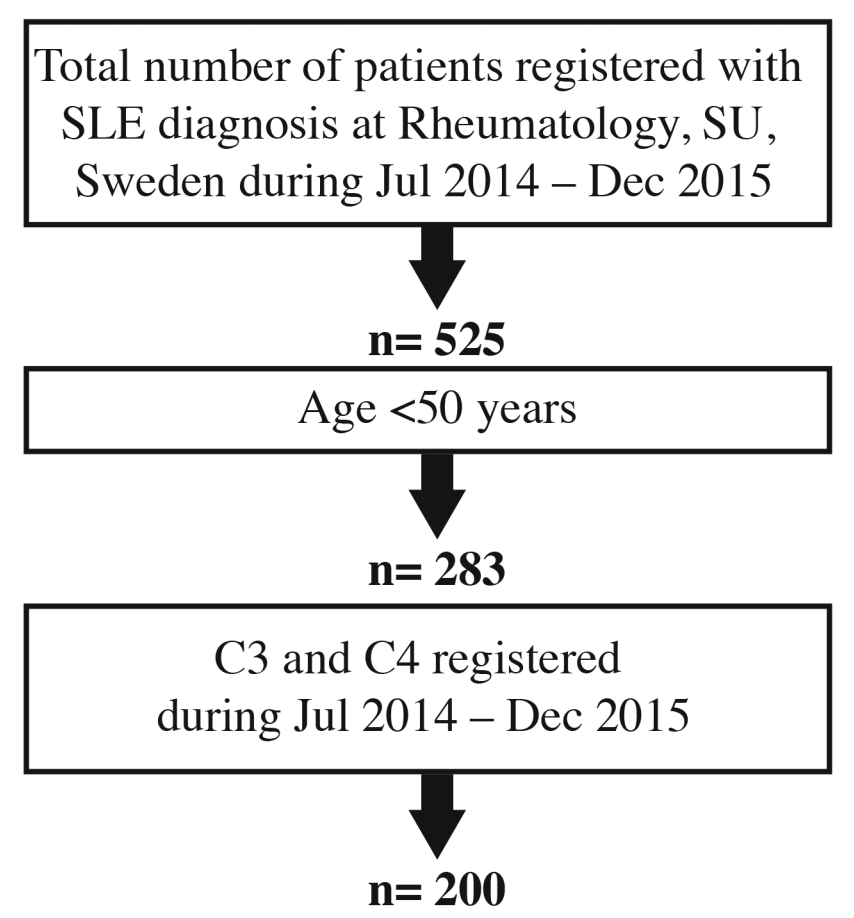

\section{SLE diagnosis fulfills SLICC criteria}

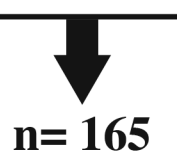

Figure 1. Flowchart of patient inclusion in the study. SU: Sahlgrenska University Hospital; SLE: systemic lupus erythematosus; SLICC: Systemic Lupus International Collaborating Clinics.

and the lowest value was calculated during this period and is referred to as the "estimated average" levels of $\mathrm{C} 3$ and $\mathrm{C} 4$.

The site of infection was recorded as well as the type of pathogen when it was given in medical records and microbiological laboratory responses. Patients who experienced at least 1 episode of infection during the study period were classified as the infection group.

Detailed information regarding the current treatment with glucocorticoids (GC), disease-modifying antirheumatic drugs (DMARD), and biological drugs during the 1.5-year period was also obtained from medical records. We estimated the average GC consumption during the period and graduated the effect into 3 groups: 0 points (no treatment); 1 point $(<10 \mathrm{mg}$ daily in average); 2 points ( $\geq 10 \mathrm{mg}$ daily in average). For CYC, a period 1 month posttreatment, and for RTX, a period up to 6 months following treatment was included because of the known longterm effects of these treatments on the immune system. In an attempt to estimate the various immunosuppressive effects of drugs in the groups "antirheumatic drugs including GC" and "antirheumatic drugs excluding GC," we classified the drugs according to a score system and calculated a total value for each patient. The values were 0 point (no treatment); 1 point (hydroxychloroquine); 2 points (other DMARD, such as azathioprine, methotrexate, tacrolimus, cyclosporine, and mycophenolate mofetil); 3 points (belimumab, RTX, and CYC). Statistical analysis. Analyses were performed using GraphPad Prism version $7.0 \mathrm{~b}$ software (GraphPad software) and by SAS (Statistical Analysis System). The statistical significances of differences between groups were assessed using the Mann-Whitney U test and the chi-square test. Pearson's correlation was used to calculate correlation coefficients. Multiple linear regression was used in different models to assess whether confounding exists. A 2-tailed $\mathrm{p}$ value $<0.05$ was considered statistically significant.

\section{RESULTS}

Opsonophagocytosis by neutrophils is largely dependent on serum levels of complement factors. To identify the $\mathrm{C} 3 \mathrm{~b}$ deposits on the bacterial surface, the GFP-expressing $S$. aureus was incubated with SLE serum with normal complement and with C3-depleted serum. Both histogram (Figure 2A) and representative images (Figure 2B) by imaging flow cytometry clearly demonstrate the presence of abundant $\mathrm{C} 3 \mathrm{~b}$ deposits on the bacterial surface after opsonization with SLE sera but not with C3-depleted sera. The phagocytic rates were greatly reduced when bacteria were opsonized with heat-inactivated sera, EDTA-plasma, and C3-depleted sera compared with SLE sera with normal $\mathrm{C} 3$ and $\mathrm{C} 4$ levels (Figure 2C), suggesting that phagocytic capacity of neutrophils in our experimental setting is largely dependent on the complement levels.

Opsonophagocytosis of $\mathrm{S}$. aureus by healthy neutrophils is downregulated in the presence of sera from SLE patients with low complement factors. To understand whether low complement levels affect bacterial opsonophagocytosis in SLE sera, S. aureus were opsonized with sera from SLE patients or with sera from healthy individuals, and opsonophagocytosis of $S$. aureus by healthy neutrophils was analyzed using imaging flow cytometry. A very low internalization rate $(11 \%)$ was seen when $S$. aureus were not opsonized with serum, whereas the internalization rate was 5 -fold higher when bacteria were preincubated with sera from healthy individuals (Figure 2D). Importantly, significantly decreased uptake of $S$. aureus by neutrophils was observed when S.aureus was opsonized with sera from SLE patients with low complement levels compared to sera from SLE patients with normal complement and healthy individuals.

We further studied the association between the internalization rate and the levels of complement factors in patients with SLE. There was a significant positive correlation between internalization rate and $\mathrm{C} 4$ levels (Figure 2E), whereas $\mathrm{C} 3 \mathrm{~d}$ levels were negatively correlated with internalization rate $(r=-0.61, p=0.02)$. C3 levels did not significantly correlate with internalization rate. Representative micrographs of neutrophils in association with GFP-expressing S. aureus are shown in Figure 2F.

Characterization of cohort of patients with SLE. To further investigate whether our in vitro results have clinical relevance, we retrospectively examined the infection incidence in relation to complement levels in a cohort of 165 young patients with SLE (age range 17-49 yrs) with median disease duration 9 years (range 1-35 yrs) at our rheumatology clinic during a 1.5 -year period. Table 1 presents the clinical characteristics and disease-related variables of patients with SLE (145 females and 20 males) included in the study. All Personal non-commercial use only. The Journal of Rheumatology Copyright (c) 2018. All rights reserved. 
A

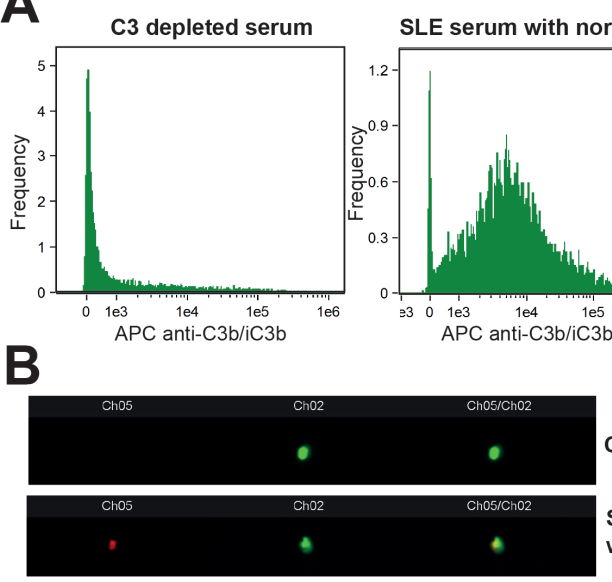

C3 depleted serum

SLE serum

with normal C3

D

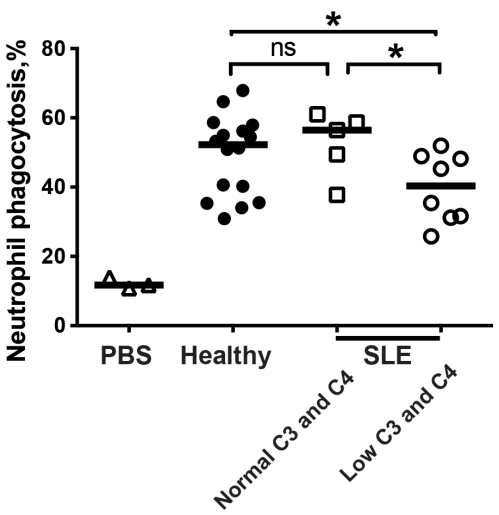

C

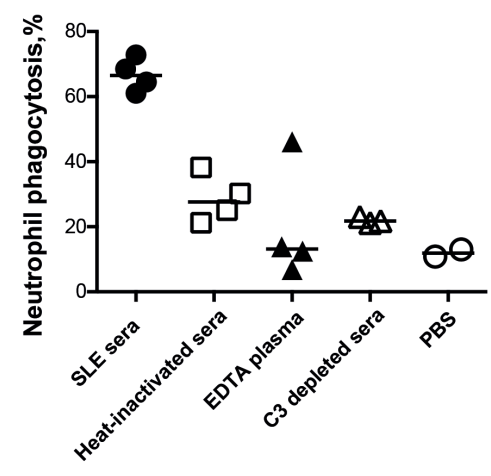

$\mathbf{F}$

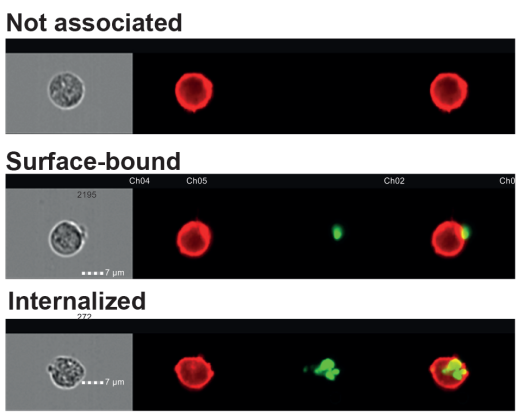

Figure 2. Opsonophagocytosis of Staphylococcus aureus by neutrophils was downregulated in SLE patients with low complement factors. The GFP-expressing S. aureus was incubated with $10 \%$ serum from SLE patients with normal complement levels and with C3-depleted serum. The C3b deposits were stained and analyzed by imaging flow cytometry. The $\mathrm{C} 3 \mathrm{~b}$-positive bacteria are shown in histogram (A) and in representative micrographs (B; C3b in red and bacteria in green). Human neutrophils isolated from healthy blood donors were incubated with GFP-expressing S. aureus that was opsonized with $10 \%$ normal sera, heat-inactivated sera, EDTA plasma, and C3-depleted sera. The phagocytosis of S. aureus by neutrophils was analyzed by an imaging flow cytometer. Image Data Exploration and Analysis Software was used to determine the interaction of the GFP-positive bacteria with neutrophils (not associated, surface bound, or internalized). (C) Percentages of human neutrophils internalized with GFP-positive S. aureus opsonized with normal sera, heat-inactivated sera, and EDTA plasma from patients with SLE, and C3-depleted sera or PBS as control. (D) Percentages of human neutrophils internalized with GFP-positive S. aureus opsonized with sera from healthy individuals $(\mathrm{n}=16)$ and SLE patients with normal $(\mathrm{n}=5)$ and low $(\mathrm{n}=8)$ complement levels. The Mann-Whitney U test was used to evaluate the statistical significance of the results. (E) Correlation between serum C4 levels and the percentage of neutrophils with internalized S. aureus. (F) Representative micrographs of neutrophils in association with GFP-expressing S. aureus analyzed by imaging flow cytometry. GFP: green fluorescent protein; SLE: systemic lupus erythematosus; PBS: phosphate buffered saline; APC: allophycocyanin.

patients fulfilled the SLICC-2012 classification criteria for SLE diagnosis. Of them, $99 \%$ had ever been tested positive with immunofluorescence for the presence of antinuclear antibodies, and $85 \%$ were ever anti-dsDNA-positive during the disease course. Sixty-eight patients had previous or present SLE kidney involvement, whereas 6 of them had undergone kidney transplantation. Over half of the patients presented or ever have had leukopenia.

In 101 patients, complement levels were analyzed 2 or more times (range 2-11), and the majority of them had stable levels of $\mathrm{C} 3$ and $\mathrm{C} 4$ during the 1.5 years. At some point during the investigated time period, $51 \%$ of patients had both low C3 and C4. Regarding the treatments, only 5 patients had no current treatment for SLE. Almost $80 \%$ of patients received hydroxychloroquine and $52 \%$ of patients had synthetic DMARD. Azathioprine was the most commonly used DMARD, followed by mycophenolate mofetil and methotrexate. Twelve patients received belimumab. Eight patients were treated with CYC infusions and 25 patients had been treated with RTX up to half a year prior to inclusion or were treated during the study period. There were 96 patients treated with GC in either an estimated high dose $(\geq 10$ $\mathrm{mg} /$ day, $16 \%$ ) or low dose (<10 mg daily, $42 \%$ ).

The diverse infections in the study population. Seventy-two patients (44\%) had at least 1 infection during the study period (range: 1-4 infections). Bacterial infections were most 
Table 1. Demographic and disease-related variables, and treatments of the 165 included patients with SLE.

\begin{tabular}{|c|c|}
\hline \multicolumn{2}{|l|}{ General information } \\
\hline Patient age, yrs & $17-49$, median 36 \\
\hline Sex, females/males & $145 / 20(87.9 / 12.1)$ \\
\hline Disease duration, yrs & 1-35, median 9 \\
\hline SLICC/ACR 1997 criteria & $165 / 146(100 / 88.5)$ \\
\hline \multicolumn{2}{|l|}{ Autoantibodies ever } \\
\hline ANA & $163(99.0)^{\mathrm{a}}$ \\
\hline Anti-dsDNA & $140(84.8)^{\mathrm{b}}$ \\
\hline Anti-SSA & $74(44.8)$ \\
\hline Anti-SSB & $27(16.4)$ \\
\hline Anti-Sm & $28(17.0)$ \\
\hline Anti-RNP & $39(23.6)$ \\
\hline Anti-Ribo P & $13(7.9)$ \\
\hline Anti-C1q & $12(7.3)$ \\
\hline Cardiolipin antibodies IgG & $42(25.5)$ \\
\hline Cardiolipin antibodies IgM & $5(3.0)$ \\
\hline$\beta_{2}$-GPI IgG & $28(17.0)$ \\
\hline$\beta_{2}$-GPI IgM & $6(3.6)$ \\
\hline Lupus anticoagulant & $26(15.8)$ \\
\hline \multicolumn{2}{|l|}{ Organ involvement ever } \\
\hline Serositis & $54(32.7)$ \\
\hline Kidney involvement & $68(41.2)^{c}$ \\
\hline CNS involvement & $37(22.4)$ \\
\hline Hemolytic anemia & $14(8.5)$ \\
\hline Leukopenia ever & $92(55.8)$ \\
\hline Thrombocytopenia ever & $56(33.9)$ \\
\hline \multicolumn{2}{|c|}{ Serum levels of complement factors (July 14-Dec. 15, 2015) } \\
\hline $\mathrm{C} 3, \mathrm{~g} / 1$ & Mean 0.76 , range $0.104-1.35 \mathrm{~g} / 1$ \\
\hline Normal C3 & $60(36.4)$ \\
\hline Low C3 & $85(51.5)$ \\
\hline Very low C3 & $20(12.1)$ \\
\hline $\mathrm{C} 4, \mathrm{~g} / \mathrm{l}$ & Mean 0.13 , range $0.019-0.93 \mathrm{~g} / 1$ \\
\hline Normal C4 & $65(39.4)$ \\
\hline Low $\mathrm{C} 4$ & $51(30.9)$ \\
\hline Very low C4 & $49(29.7)$ \\
\hline Low $\mathrm{C} 3$ and $\mathrm{C} 4$ & $84(50.9)$ \\
\hline High C3d & $71(43.0)$ \\
\hline \multicolumn{2}{|c|}{ Treatment (July 14-Dec. 15,2015 ) } \\
\hline No treatment & $5(3.0)$ \\
\hline Hydroxychloroquine & $130(78.8)$ \\
\hline Azathioprine & $60(36.4)$ \\
\hline Mycophenolate mofetil & $42(25.5)$ \\
\hline Methotrexate & $16(9.7)$ \\
\hline Tacrolimus & $5(3.0)$ \\
\hline Cyclosporine & $6(3.6)$ \\
\hline Belimumab & $12(7.3)$ \\
\hline Rituximab & $25(15.2)$ \\
\hline Cyclophosphamide & $8(4.8)$ \\
\hline No glucocorticoids & $69(41.8)$ \\
\hline Prednisone $<10 \mathrm{mg} /$ day & $70(42.4)$ \\
\hline Prednisone $\geq 10 \mathrm{mg} /$ day & $26(15.8)$ \\
\hline
\end{tabular}

Data are $\mathrm{n}(\%)$ unless otherwise indicated. ${ }^{\mathrm{a}} 1$ missing data. ${ }^{\mathrm{b}} 3$ missing data. ${ }^{c} 6$ patients had kidney transplants. SLE: systemic lupus erythematosus; SLICC/ACR: Systemic Lupus International Collaborating Clinics/American College of Rheumatology; ANA: antinuclear antibody; $\beta_{2}$-GPI: $\beta_{2}$-glycoprotein I; CNS: central nervous system.

common and 59 patients had at least 1 bacterial infection; 11 patients at least 1 viral infection, 9 patients at least 1 fungal infection, and 1 patient have had a parasitic infection. Some patients had both bacterial and viral/fungal infections (Supplementary Table 1, available with the online version of this article).

The distribution of different infections is presented in Table 2. The most common bacterial infection in patients with SLE was urinary tract infection with 37 identified cases, followed by skin infections with 10 cases, pneumonia ( 6 cases), and sepsis (6 cases). Herpes simplex oral and genital infections were the most common viral infections (7 cases).

The association of complement factors and infection incidence. The patients with SLE were divided into 3 groups according to their blood levels of complement factors (normal, low, and very low levels). The percentage of SLE patients with at least 1 infection and the frequency of infections in patients with SLE were compared among groups (Supplementary Figure 1, available with the online version of this article). Patients with low complement levels had a tendency toward increased incidence of infections; this was mainly evident for low C3 levels (Supplementary Figure 1A and 1B). However, the results were not statistically significant. There was no difference when bacterial infections were examined separately.

Correlation between infection incidence, disease-related variables, and treatments. Table 3 shows the correlation between infection incidence and disease-related variables and treatments. There was a significant correlation between

Table 2. Distribution of infections in 165 patients with SLE during a period of 1.5 years.

\begin{tabular}{|c|c|}
\hline Bacterial infections & $\mathrm{n}=92$ \\
\hline Urinary tract infection & 37 (9 relapsed) \\
\hline Skin infections & 10 (3 relapsed) \\
\hline Pneumonia & 6 \\
\hline Sepsis & 6 \\
\hline Tonsillitis & 5 \\
\hline Otitis media & 1 \\
\hline Sinusitis & 2 \\
\hline Unspecified bacterial URI & 7 (2 relapsed) \\
\hline Conjunctivitis & 4 \\
\hline Gastroenteritis & 4 \\
\hline Bacterial vaginosis & 2 \\
\hline $\begin{array}{l}\text { Other bacterial infections (psoas abscess/spon } \\
\text { epididymitis, uterine infection, otitis externa, } \\
\text { infection after dental procedures, chlamydia, } \\
\text { erythema migrans, mycoplasma genitalia). }\end{array}$ & ylitis, \\
\hline Viral infections & $\mathrm{n}=13$ \\
\hline Herpes zoster & 4 \\
\hline Herpes simplex oral and genital infections & 7 (1 relapsed) \\
\hline $\begin{array}{l}\text { Other viral infections (varicella-zoster virus } \\
\text { meningitis, verrucae) }\end{array}$ & 2 \\
\hline Fungal infections & $\mathrm{n}=9$ \\
\hline Oral candida & 3 \\
\hline Genital fungal infections & 4 \\
\hline Skin fungal infections & 2 \\
\hline Parasitic infections & $\mathrm{n}=1$ \\
\hline Entameba histolytica & 1 \\
\hline
\end{tabular}

SLE: systemic lupus erythematosus; URI: upper respiratory infection. 
Table 3. The association between infections and disease-related variables and treatments.

\begin{tabular}{|c|c|c|c|c|}
\hline \multirow[t]{2}{*}{ Variables } & \multicolumn{2}{|c|}{ All Infections, $\mathrm{n}=115$} & \multicolumn{2}{|c|}{ Bacterial Infections, $\mathrm{n}=92$} \\
\hline & $\mathrm{p}$ & $\mathrm{r}$ & $\mathrm{p}$ & $\mathrm{r}$ \\
\hline Age & ns & & ns & \\
\hline Disease duration & $\mathrm{ns}$ & & $\mathrm{ns}$ & \\
\hline Kidney involvement ever & ns & & $\mathrm{ns}$ & \\
\hline CNS/PNS involvement ever & ns & & ns & \\
\hline C3 mean estimated & $\mathrm{ns}$ & & ns & \\
\hline $\mathrm{C} 4$ mean estimated & ns & & $<0.05$ & -0.16 \\
\hline Anti-dsDNA levels & $<0.05$ & 0.19 & ns & \\
\hline Leukopenia & $\mathrm{ns}$ & & ns & \\
\hline $\begin{array}{l}\text { Antirheumatic drugs, incl. } \\
\text { glucocorticoids }\end{array}$ & $<0.001$ & 0.20 & 0.001 & 0.20 \\
\hline Glucocorticoids & $<0.01$ & 0.19 & $<0.001$ & 0.24 \\
\hline High dose ( $\geq 10 \mathrm{mg} /$ day) & 0.01 & 0.24 & $<0.01$ & 0.28 \\
\hline Low dose $(<10 \mathrm{mg} /$ day $)$ & $\mathrm{ns}$ & & ns & \\
\hline CYC and/or RTX & $\mathrm{ns}$ & & $<0.05$ & 0.22 \\
\hline
\end{tabular}

Significant data are in bold face. Pearson's test was used to calculate the correlation coefficients for continuous and multicategorical variables. The chi-squared test was used for dummy variables. CNS: central nervous system; PNS: peripheral nervous system; CYC: cyclophosphamide; RTX: rituximab; ns: not significant.

incidence of all infections and anti-dsDNA levels $(\mathrm{p}<0.05)$, all antirheumatic drugs including GC ( $p<0.001)$, and GC only $(\mathrm{p}<0.01)$. However, the only correlation between infection incidence and GC remained significant when the multiple linear regression analysis was applied. We analyzed the effect of different doses of GC on infection incidence. Our data suggest that high dose of GC (equivalent to prednisone $\geq 10 \mathrm{mg} /$ day) significantly increased the total infection risk $(\mathrm{p}=0.01)$.

The bacterial infections were further analyzed separately. Significant correlation was also found between bacterial infections and antirheumatic drugs including GC $(\mathrm{p}=0.001)$, and GC only $(\mathrm{p}<0.001)$. Interestingly, bacterial infections were also associated with low C4 levels $(\mathrm{p}<0.05)$ and CYC and/or RTX ( $p<0.05)$. In a model of multiple linear regression, the association between bacterial infections and C4 levels, CYC and/or RTX, as well as high dose of GC, remained significant. This suggests that GC in high dose (prednisone $\geq 10 \mathrm{mg} /$ day), low C4 levels, as well as CYC and/or RTX are independent risk factors for bacterial infections in patients with SLE.

Owing to a low incidence rate of viral, fungal, and parasitic infections, no detailed analysis was performed.

Infection risks in patients with SLE. We further analyzed the infection risks in patients treated with high-dose prednisone and CYC and/or RTX. Treatment with high-dose prednisone ( $\geq 10 \mathrm{mg} /$ day) in patients with SLE almost triples the risk for all infections (OR 2.88, CI 1.20-6.93) and especially for bacterial infections (OR 3.57, CI 1.49-8.51). Also, treatment with CYC and/or RTX doubles the risk for bacterial infection (OR 2.26, CI 1.05-4.98).

\section{DISCUSSION}

In our present study, we have provided the experimental data suggesting that low serum levels of complement factors in patients with SLE lead to impaired opsonophagocytosis of bacteria in vitro.

Downregulated neutrophil functions have been shown in mouse models for SLE and also in patients with SLE. In MRL/lpr mice with SLE-like disease, neutrophils exhibit defect in Fc receptor-mediated phagocytosis and reduced migration capacity toward infection sites, a process mediated by the complex of $\mathrm{IgG}$ and active transforming growth factor (TGF)- $\beta$ in blood $25,26,27$. In line with the animal data, neutrophils from patients with SLE have impaired phagocytic ability and diminished chemotaxis upon interleukin 8 stimulation compared with healthy controls ${ }^{9,10}$. In addition, the production of reactive oxygen species in neutrophils is lower in patients with SLE, a condition associated with organ damage in patients with $\mathrm{SLE}^{11}$. Because the neutrophils were isolated from healthy blood donors and bacteria were opsonized with sera from patients with SLE, the downregulated opsonophagocytic capacity that we observed can therefore be explained only by the serum factors in patients with SLE. We speculate that a more pronounced effect might be seen if the autologous neutrophils were used.

Most likely, the downregulation of opsonophagocytosis is due to lower complement factors in patients with SLE. Activation of complement is known to be mediated through 3 different pathways: classical, lectin, and alternative, all of which share the common step of activating the central complement component $\mathrm{C} 3$, which generates bacterium-bound opsonin $\mathrm{C} 3 \mathrm{~b}$ and anaphylatoxin $\mathrm{C} 3 \mathrm{a}$. In our current study, bacterial opsonization was weaker in the sera obtained from SLE patients with low complement levels compared with sera from healthy individuals and sera from SLE patients with normal complement levels. Not surprisingly, weaker opsonization resulted in downregulated phago-

Personal non-commercial use only. The Journal of Rheumatology Copyright (c) 2018. All rights reserved. 
cytosis of $S$. aureus by neutrophils in vitro. The positive correlation between the opsonophagocytic capacity of neutrophils and the serum levels of complement factors further strengthens the above-mentioned theory. Interestingly, $\mathrm{C} 3 \mathrm{a}$, liberated in the course of complement activation, was shown to exhibit antimicrobial activity ${ }^{28,29}$. Direct anti-microbial activity of C3a might also enhance host innate defense against invading pathogens.

Our in vitro data suggest that patients with low levels of complement factors might have an increased susceptibility to infections as a result of diminished opsonization and decreased antimicrobial activity. However, the only significant correlation was found between $\mathrm{C} 4$ levels and the bacterial infection frequency in our cohort. There are 2 possible explanations for the discrepancy between in vitro finding and our retrospective patient data: (1) in vitro ImageStream analysis method that combines the phenotyping abilities of flow cytometry with the detailed images from microscopy is a sensitive method able to detect the differences that may not be clinically relevant in vivo; and (2) the sample size of our cohort is relatively small and the statistical power is probably too weak to reach the statistical significance. The latter explanation might be more rational, because low levels of complement factors have been shown in several reports as independent risk factors for the development of severe infections and acquiring drug-resistant bacteria in patients with $\operatorname{SLE}^{3,7,13}$.

There are some other serum factors including anticardiolipin antibodies (aCL) and TGF- $\beta 1$ in patients with SLE exhibiting the inhibitory effect on neutrophils. It has been shown that aCL in higher concentration inhibits the neutrophil phagocytosis through suppression of $\mathrm{C} 3 \mathrm{~b} / \mathrm{C} 4 \mathrm{~b}$ and $\mathrm{Fc}$ receptors on the neutrophil surface ${ }^{30}$. Thus, there might be even higher infection risk for SLE patients with secondary antiphospholipid syndrome, who might have both low complement factor levels and high levels of aCL. Indeed, this situation is not rare, because complement activation and consumption are common in patients with antiphospholipid syndrome $^{31}$. The complex formation of IgG and TGF- $\beta 1$ was shown to be potent for suppression of neutrophil function and host defense against bacterial infection ${ }^{25}$. Our data, however, demonstrated that serum levels of both total and active TGF- $\beta 1$ are downregulated in patients with $\mathrm{SLE}^{32}$, being opposed to the hypothesis that TGF- $\beta 1$ might be another serum factor inhibiting neutrophil functions. It has been shown that cryoglobulin fraction of immune complexes in SLE sera might also affect the opsonization by binding to the protein A on the staphylococcal cell wall ${ }^{33}$. Also, there is a considerable variation in the levels of antistaphylococcal antibodies in different individuals, which could affect opsonization $^{34,35}$.

A systematic literature review suggests that there is no evidence of a significant association between overall reduction of white blood cells and infection occurrence, whereas lymphopenia/neutropenia might be associated with the risk of major infections ${ }^{36}$. Our data provide other supporting evidence for this conclusion: we found no association between infections and leukopenia in our patient cohort. High-dose prednisone and CYC are well-recognized risk factors for infections $s^{3,4,5,6}$. The first 6 months after RTX treatment and use of more than 3 courses were also shown to be associated with increased susceptibility for infections ${ }^{4}$, while antimalarial treatment has a protective effect against major infections ${ }^{37}$. In our present study, high-dose prednisone was the most stable predictive factor for infections. Our data strongly suggest that to reduce the infection incidence in SLE, it is advisable to keep the prednisone dose as low as possible in chronic treatment.

Our study demonstrates for the first time, to our knowledge, that low complement levels in the blood of patients with SLE lead to downregulated phagocytosis of bacteria by healthy neutrophils in vitro. In line with previous reports, high-dose GC (prednisone $\geq 10 \mathrm{mg} /$ day) significantly increase the infection risk in patients with SLE.

\section{ONLINE SUPPLEMENT}

Supplementary material accompanies the online version of this article.

\section{REFERENCES}

1. Fessler BJ. Infectious diseases in systemic lupus erythematosus: risk factors, management and prophylaxis. Best Pract Res Clin Rheumatol 2002;16:281-91.

2. Petri M, Genovese M. Incidence of and risk factors for hospitalizations in systemic lupus erythematosus: a prospective study of the Hopkins Lupus Cohort. J Rheumatol 1992;19:1559-65.

3. Al-Rayes H, Al-Swailem R, Arfin M, Sobki S, Rizvi S, Tariq M. Systemic lupus erythematosus and infections: a retrospective study in Saudis. Lupus 2007;16:755-63.

4. Danza A, Ruiz-Irastorza G. Infection risk in systemic lupus erythematosus patients: susceptibility factors and preventive strategies. Lupus 2013;22:1286-94.

5. Zandman-Goddard G, Shoenfeld Y. SLE and infections. Clin Rev Allergy Immunol 2003;25:29-40.

6. Barrera-Vargas A, Gomez-Martin D, Merayo-Chalico J, Ponce-de-Leon A, Alcocer-Varela J. Risk factors for drug-resistant bloodstream infections in patients with systemic lupus erythematosus. J Rheumatol 2014;41:1311-6.

7. Bosch X, Guilabert A, Pallares L, Cerveral R, Ramos-Casals M, Bove A, et al. Infections in systemic lupus erythematosus: a prospective and controlled study of 110 patients. Lupus 2006;15:584-9.

8. Gladman DD, Hussain F, Ibanez D, Urowitz MB. The nature and outcome of infection in systemic lupus erythematosus. Lupus 2002;11:234-9.

9. de la Fuente H, Richaud-Patin Y, Jakez-Ocampo J, Gonzalez-Amaro $\mathrm{R}$, Llorente L. Innate immune mechanisms in the pathogenesis of systemic lupus erythematosus (SLE). Immunol Lett 2001; 77:175-80.

10. Wu SA, Yeh KW, Lee WI, Yao TC, Kuo ML, Huang B, et al. Impaired phagocytosis and susceptibility to infection in pediatric-onset systemic lupus erythematosus. Lupus 2013; 22:279-88.

11. Bengtsson AA, Pettersson A, Wichert S, Gullstrand B, Hansson M, Hellmark T, et al. Low production of reactive oxygen species in

Personal non-commercial use only. The Journal of Rheumatology Copyright (c) 2018. All rights reserved 
granulocytes is associated with organ damage in systemic lupus erythematosus. Arthritis Res Ther 2014;16:R120.

12. Yu CL, Chang KL, Chiu CC, Chiang BN, Han SH, Wang SR Defective phagocytosis, decreased tumour necrosis factor-alpha production, and lymphocyte hyporesponsiveness predispose patients with systemic lupus erythematosus to infections. Scand J Rheumatol 1989;18:97-105.

13. Merayo-Chalico J, Gomez-Martin D, Pineirua-Menendez A, Santana-De Anda K, Alcocer-Varela J. Lymphopenia as risk factor for development of severe infections in patients with systemic lupus erythematosus: a case-control study. QJM 2013;106:451-7.

14. Botto M, Walport MJ. C1q, autoimmunity and apoptosis. Immunobiology 2002;205:395-406.

15. Walport MJ. Complement and systemic lupus erythematosus. Arthritis Res 2002;4 Suppl 3:S279-93.

16. Arora V, Verma J, Dutta R, Marwah V, Kumar A, Das N. Reduced complement receptor 1 (CR1, CD35) transcription in systemic lupus erythematosus. Mol Immunol 2004;41:449-56.

17. Macedo AC, Isaac L. Systemic lupus erythematosus and deficiencies of early components of the complement classical pathway. Front Immunol 2016;7:55.

18. Sturfelt G, Truedsson L. Complement in the immunopathogenesis of rheumatic disease. Nat Rev Rheumatol 2012;8:458-68.

19. Tan EM, Cohen AS, Fries JF, Masi AT, McShane DJ, Rothfield NF, et al. The 1982 revised criteria for the classification of systemic lupus erythematosus. Arthritis Rheum 1982;25:1271-7.

20. Hochberg MC. Updating the American College of Rheumatology revised criteria for the classification of systemic lupus erythematosus. Arthritis Rheum 1997;40:1725.

21. Petri M, Orbai AM, Alarcon GS, Gordon C, Merrill JT, Fortin PR, et al. Derivation and validation of the Systemic Lupus International Collaborating Clinics classification criteria for systemic lupus erythematosus. Arthritis Rheum 2012;64:2677-86.

22. Boyum A, Lovhaug D, Tresland L, Nordlie EM. Separation of leucocytes: improved cell purity by fine adjustments of gradient medium density and osmolality. Scand J Immunol 1991;34:697-712.

23. Na M, Jarneborn A, Ali A, Welin A, Magnusson M, Stokowska A, et al. Deficiency of the complement component 3 but not factor B aggravates staphylococcus aureus septic arthritis in mice. Infect Immun 2016;84:930-9.

24. Na M, Mohammad M, Fei Y, Wang W, Holdfeldt A, Forsman H, et al. Lack of receptor for advanced glycation end products leads to less severe staphylococcal skin infection but more skin abscesses and prolonged wound healing. J Infect Dis 2018 Jan 10 (E-pub ahead of print).

25. Caver TE, O’Sullivan FX, Gold LI, Gresham HD. Intracellular demonstration of active TGFbeta1 in B cells and plasma cells of autoimmune mice. IgG-bound TGFbeta1 suppresses neutrophil function and host defense against Staphylococcus aureus infection. J Clin Invest 1996;98:2496-506.

26. Gresham HD, Ray CJ, O’Sullivan FX. Defective neutrophil function in the autoimmune mouse strain MRL/lpr. Potential role of transforming growth factor-beta. J Immunol 1991;146:3911-21.

27. Lowrance JH, O'Sullivan FX, Caver TE, Waegell W, Gresham HD. Spontaneous elaboration of transforming growth factor beta suppresses host defense against bacterial infection in autoimmune MRL/lpr mice. J Exp Med 1994;180:1693-703.

28. Nordahl EA, Rydengard V, Nyberg P, Nitsche DP, Morgelin M, Malmsten M, et al. Activation of the complement system generates antibacterial peptides. Proc Natl Acad Sci U S A 2004;101:16879-84.

29. Koch TK, Reuter M, Barthel D, Bohm S, van den Elsen J, Kraiczy $\mathrm{P}$, et al. Staphylococcus aureus proteins Sbi and Efb recruit human plasmin to degrade complement C3 and C3b. PLoS One 2012;7:e47638.

30. Yu CL, Sun KH, Tsai CY, Wang SR. Inhibitory effects of anticardiolipin antibodies on lymphocyte proliferation and neutrophil phagocytosis. Ann Rheum Dis 1991;50:903-8.

31. Oku K, Atsumi T, Bohgaki M, Amengual O, Kataoka H, Horita T, et al. Complement activation in patients with primary antiphospholipid syndrome. Ann Rheum Dis 2009;68:1030-5.

32. Jin T, Almehed K, Carlsten H, Forsblad-d'Elia H. Decreased serum levels of TGF-beta1 are associated with renal damage in female patients with systemic lupus erythematosus. Lupus 2012;21:310-8.

33. Nived O, Linder C, Odeberg H, Svensson B. Reduced opsonisation of protein A containing Staphylococcus aureus in sera with cryoglobulins from patients with active systemic lupus erythematosus. Ann Rheum Dis 1985;44:252-9.

34. Dryla A, Prustomersky S, Gelbmann D, Hanner M, Bettinger E, Kocsis B, et al. Comparison of antibody repertoires against Staphylococcus aureus in healthy individuals and in acutely infected patients. Clin Diagn Lab Immunol 2005;12:387-98.

35. Monteil MA, Kaniuk AS, Hobbs JR. Staphylococcal opsonization and anti-Staphylococcus aureus IgG subclass antibodies in patients with severe or recurrent $\mathrm{S}$. aureus infections. FEMS Microbiol Immunol 1990;2:259-62.

36. Carli L, Tani C, Vagnani S, Signorini V, Mosca M. Leukopenia, lymphopenia, and neutropenia in systemic lupus erythematosus: Prevalence and clinical impact-A systematic literature review. Semin Arthritis Rheum 2015;45:190-4.

37. Ruiz-Irastorza G, Olivares N, Ruiz-Arruza I, Martinez-Berriotxoa A, Egurbide MV, Aguirre C. Predictors of major infections in systemic lupus erythematosus. Arthritis Res Ther 2009;11:R109. 